\title{
Fertility-sparing treatment for epithelial ovarian cancer: a literature review
}

\author{
Milagros Pérez-Quintanilla ${ }^{1 \#}$, Sarish del Real-Ordoñez ${ }^{2 \#}$, Lenny Gallardo-Alvarado ${ }^{3}$, David Cantu-de Leon ${ }^{4}$ \\ ${ }^{1}$ Department of Gynecology and Obstetrics, Centro Medico ABC, Mexico City, Mexico; ${ }^{2}$ Department of Gynecologic Oncology, Centro Oncológico \\ Región Sureste Coahuila, Saltillo, Mexico; ${ }^{3}$ Clinical Research Department, ${ }^{4}$ Direction of Research, Instituto Nacional de Cancerología, Mexico City, Mexico \\ Contributions: (I) Conception and design: D Cantu-de Leon; (II) Administrative support: L Gallardo-Alvarado; (III) Provision of study materials \\ or patients: All authors; (IV) Collection and assembly of data: D Cantu-de Leon, M Pérez-Quintanilla, S del Real-Ordoñez; (V) Data analysis \\ and interpretation: D Cantu-de Leon, M Pérez-Quintanilla, S del Real-Ordoñez; (VI) Manuscript writing: All authors; (VII) Final approval of \\ manuscript: All authors. \\ \#These authors contributed equally to this work. \\ Correspondence to: David Cantu-de Leon, MD, MSc, PhD. Direction of Research, Instituto Nacional de Cancerología, San Fernando 22 avenue, \\ Tlalpan, ZP 14080, Mexico City, Mexico. Email: dcantude@gmail.com.
}

\begin{abstract}
Epithelial ovarian cancer is more common in postmenopausal women, with a mean age at diagnosis of 65 years; however, it has been documented that $3 \%$ to $17 \%$ of epithelial ovarian cancer cases are diagnosed in women younger than 40 years, with an overall survival of up to $90 \%$ when diagnosed in early-stage disease. The development of fertility-sparing approaches represents one of the most significant advances in the gynecologic oncology field. These approaches can have satisfactory outcomes on fertility with excellent oncological results in premenopausal women with early-stage epithelial ovarian cancer and the desire to preserve fertility. Because of the low occurrence of this specific population, randomized trials have not been performed. However, several retrospective series suggest that in certain cases, fertility-sparing surgery is safe, with low rates of recurrence and favorable reproductive outcomes in accordance to the new techniques in reproductive biology; therefore, fertility-sparing approaches must be discussed with young female patients with epithelial ovarian cancer or in patients that desire to preserve fertility or to maintain ovarian function and to improve quality of life in this particular group of individuals. In this review, we present the published evidence, including oncologic and reproductive results, as well as fertility-sparing surgical options, in the field in the last 10 years.
\end{abstract}

Keywords: Conservative treatment; fertility-sparing surgery; epithelial ovarian cancer

Submitted Jan 21, 2020. Accepted for publication Jun 17, 2020.

doi: $10.21037 /$ cco-20-38

View this article at: http://dx.doi.org/10.21037/cco-20-38

\section{Introduction}

Ovarian cancer represents the eighth leading cause of death in women worldwide and is the second leading cause of death due to gynecologic cancer in developed countries. According to statistics from 2018, an estimated 295,444 new cases and 187,799 deaths per year occur because of this disease. Incidence rates vary by region and economic development level; in emerging economies, the rate is 5.7 per 100,000 women, while in developed countries, the rate is 7 per 100,000 women $(1,2)$.

Ovarian cancer is histologically classified into different subtypes with diverse biological behaviors and prognoses. The most common histologic classification is ovarian cancer of epithelial origin (EOC), accounting for $90 \%$ of ovarian cancer cases (3). EOC is most commonly diagnosed after menopause (average age 65 years), although between 3\% and $17 \%$ of cases are diagnosed in women younger than 40 years (4).

In patients who have early disease confined to one or 
both of the ovaries or cancer that has spread to the uterus, fallopian tubes or other sites in the pelvis, surgical staging is essential to confirm the clinical stage that will later guide adjuvant therapy (3). This review aims to summarize the current surgical techniques and fertility-sparing options for young patients with early-stage EOC and the desire to preserve fertility without jeopardizing the oncologic results.

\section{Surgical assessment}

Management of EOC requires adequate surgical staging. Each patient who undergoes a surgical approach due to malignant suspicion must be sufficiently informed about the possibility for the extension of surgical intervention if malignant disease is reported in the trans-surgical pathology study. Staging surgery is based on two points:

(I) To provide evidence for future adjuvant treatment with different treatment modalities;

(II) To improve the rates of survival and recurrence (5).

The mechanisms of metastasis of the disease are still not clear. EOC spreads through three different pathways: peritoneal surfaces, lymphatics, and blood. Peritoneal invasion from ovarian cancer is carried out by the direct extension of the primary tumor site towards neighboring organs, such as the bladder and the small intestine, or by the peritoneal liquid transporting malignant cells (6). Peritoneal metastases in clinical stages (CS) I/II have been reported in the literature by the identification of malignant cells-malignant cells were found in up to $22 \%$ of ascites or peritoneal washings, $9 \%$ of diaphragm biopsies and $8 \%$ of peritoneal biopsies (7).

It is believed that cancer cells follow the lymphatic ducts that accompany the ovarian artery and vein by the pelvic infundibular ligament towards the para-aortic lymph nodes; nevertheless, it is common to identify pelvic lymph node metastases. These cancer cells have a different dissemination path, likely following the parauterine vessels localized in the broad ligament until reaching the uterine vessels and, from there, towards the iliac vessels. The incidence of lymphatic node metastases in clinical stage I/II is $4.0 \%$ for well-differentiated tumors (grade 1), $16.5 \%$ for grade 2 tumors and $20 \%$ for poorly differentiated tumors. Lymph node metastases are infrequent in mucinous-subtype EOC and, for this reason, no lymph node dissection is required as a part of staging in the mucinous subtype of early-stage disease (8). Regarding localization, in unilateral EOC, pelvic and contralateral para-aortic lymph nodes were positive in $16.1 \%$ and $18.0 \%$ of cases, respectively (9).
With the standard surgical methods, the hormonal and reproductive functions are significantly affected in premenopausal patients. For this reason, less radical treatment options are continually being sought for this group of patients. The main features to define candidate patients for these less radical procedures are as follows:

(I) Patients with suspected clinical stage I disease by computed tomography.

(II) Patients younger than 40 years at diagnosis.

(III) Patients wishing to preserve fertility before seeking surgical treatment.

If the patients meet the criteria above, it is necessary to inform them about the risks of fertility-sparing treatment.

Surgical treatment consists of unilateral salpingooophorectomy; peritoneal assessment, including cytology exam of ascites or peritoneal washings, palpation, and systematic examination of the entire abdominal cavity; and pelvic and para-aortic lymphadenectomy, as well as omentectomy $(9,10)$. The main differences between fertility-sparing surgery and routine ovarian surgery are compiled in Table $1(5,10)$.

The main requirement for choosing a less invasive treatment to preserve fertility is to have a priori a good disease prognosis, exceeding $95 \%$ of the 5 -year survival rate (11). The Fertility Task Force of the European Society of Gynecologic Oncology only recommends fertility-sparing surgery for patients with early-stage EOC (except for clear cell carcinoma) with histological grades 1 and 2 (12).

\section{Surgical approach}

An important aspect to consider is the surgical approach, either laparotomy or laparoscopy. For a surgeon to decide which is the better approach, it is crucial to be aware of the evidence of specific complications. Laparotomy decreases the incidence of tumor breaks and leaks during surgery $(88 \%$ laparoscopy vs. 9\% laparotomy), especially in tumors larger than $10 \mathrm{~cm}$. The risk of this complication by laparoscopy treatment decreases with the use of a protective bag (13). Laparoscopy results in fewer peritoneal adherences than laparotomy, an essential issue that affects the probability of a successful pregnancy. Most of the information about these two types of surgical management comes from small case series of single institutions; there is only one multicentric study about the comparison of laparoscopy and laparotomy, which was published by Ghezzi et al. The study recruited 65 patients who underwent fertility-sparing and staging surgery by laparoscopy. They reported similar outcomes in 
Table 1 Comparison of cytoreductive and fertility-sparing surgical procedures

\begin{tabular}{|c|c|c|}
\hline Surgical staging procedure & $\begin{array}{c}\text { Cytoreductive ovarian } \\
\text { surgery }\end{array}$ & $\begin{array}{c}\text { Fertility-sparing } \\
\text { surgery }\end{array}$ \\
\hline Surgeon: Gynecologic Oncologist (Category 1) & $\sqrt{ }$ & $\sqrt{ }$ \\
\hline Peritoneal cytology & $\sqrt{ }$ & $\sqrt{ }$ \\
\hline Biopsies of the peritoneal paracolic gutters and undersurfaces of the diaphragm & $\sqrt{ }$ & $\sqrt{ }$ \\
\hline Hysterectomy & $\sqrt{ }$ & \\
\hline Unilateral salpingo-oophorectomy & -- & $\sqrt{ }$ \\
\hline Bilateral salpingo-oophorectomy & $\sqrt{ }$ & -- \\
\hline
\end{tabular}

terms of disease-free survival and overall survival, definitive results were not obtained with respect to the fertility rate, and more studies are necessary to clarify this point $(14,15)$.

The risk of recurrence is low, $8 \%$ and $10 \%$ in clinical stage IA and IC, respectively. It has been suggested to complete the surgery after patients have achieved their fertility goals $(16,17)$.

The National Comprehensive Cancer Network (NCCN) guidelines support fertility-sparing surgery performed by a gynecologic-oncologist only for clinical stage IA based on scientific evidence of effective oncological results. In young early-stage EOC patients, endocrine function preservation can be more important than reproductive function preservation; therefore, adequate counseling and the delay of definitive surgical management with close follow-up are recommended. Genetic risk assessment and counseling should also be implemented to identify carriers of the $B R C A$ mutation or other hereditary cancer genes related to EOC (10).

\section{Fertility-sparing indications $(10,12,18,19)$}

* Unilateral ovarian tumor.

* Histology grades 1 or 2 .

* FIGO clinical stage IA and IC of mucinous, serous, endometrioid, or mixed histological types of tumors.

* Women younger than 40 years of age.

* An expert multidisciplinary care team composed of gynecologic oncologists, oncology pathologists, reproductive biology experts and genetic counselors is required for treatment.

\section{Clinical stage IC}

Before the current FIGO classification was published in 2018, patients in clinical stage IC were grouped by several features that impact survival rates $(13,17)$. In 2014 , Kajiyama $e t a l$. published a multicenter study that included 94 patients with clinical stage I disease who were treated with fertility-sparing surgery to identify prognostic factors associated with recurrence. They reported that there were a total of 14 recurrences $(14.9 \%)$ and that 11 patients died because of disease recurrence. The 5 -year disease-free survival rate was $84.3 \%$. The patients with clinical stage IC were independently assessed; the study did not report a significant difference in disease-free survival between women with IA and IC grade 1 disease, with $\mathrm{P}=0.8658$ (mucinous vs. clear cells) and $\mathrm{P}=0.0951$ (mucinous vs. others). Patients with clinical stage IC and histology grades 2 and $3 \mathrm{had}$ a recurrence of the disease of $100 \%$ in clear cell tumors, $10 \%$ in mucinous tumors, and $37.5 \%$ in tumors of any other histological types. Patients with grade 2 and 3 tumors showed a worse prognosis than patients with grade 1 tumors $(\mathrm{P}=0.0004)(20)$.

\section{Bilateral tumors (clinical stage II)}

For women with bilateral borderline ovarian tumors, unilateral oophorectomy and contralateral cystectomy have 
been the customary surgical approaches in women with the desire to preserve fertility. In 2006, Yokoyama et al. evaluated ultraconservative management with bilateral cystectomy in patients with borderline tumors and observed better fertility results ( $n=32$ ). At the follow-up at 81 months, no significant differences in the rates of recurrence were observed between the patients who had ultraconservative management and patients who underwent unilateral oophorectomy combined with contralateral cystectomy (60\% vs. 59\%). Recurrence in the conservatively managed group occurred earlier than in the bilateral cystectomy group (16 vs. 48 months), and multiple recurrences were more probable in the conservatively managed group $(23 \%$ vs. $0 \%$ ). There were no cases of invasive cancer recurrences. Fertility results were better after bilateral cystectomy than after unilateral oophorectomy and contralateral cystectomy (pregnancy rate: $93 \%$ vs. 53\%) (21). Current evidence is limited in fertility-sparing EOC clinical stage II, given the bilateral ovary involvement and the surgical treatment required for appropriate staging (22).

\section{Histology}

\section{Histological grade 3 (G3)}

In 2016, Ghezzi et al. published one of the most extensive retrospective series of EOC, including 1,189 patients with early clinical stage disease and 432 women who were treated conservatively; clinical stage IC and histological G3 were the only independent predictors of survival (14). Fruscio et al., in a retrospective study, found a higher distal recurrence rate in patients with histological grade 3 (HR: 4.2, 95\% CI: 1.5-11.7, P=0.0067; OS: HR: 7.6, 95\% CI: 2.0-29.3, $\mathrm{P}=0.0032)(22)$.

\section{Clear cells}

The clear cell subtype of EOC has been associated with a worse prognosis due to its relative resistance towards first-line platinum-based treatment. In 2008, Kajiyama et al. compared two groups of patients with clear cell carcinoma in clinical stage I; sixteen patients were treated with fertility-sparing staging surgery and 205 were treated with radical surgery. The overall survival and the diseasefree survival rates were not significantly different between the two groups. Patients with clear cell carcinoma who underwent fertility-sparing surgery showed neither overall survival nor disease-free survival differences compared with other histological subtypes (23). Despite the small number of patients included, the authors suggested that fertility-sparing treatment could be used for clear cell tumors. In 2017, a retrospective study was published by Nasioudis et al. based on the statistics of the Surveillance, Epidemiology, and End Results Program (SEER) to investigate the oncological outcomes of uterine and ovarian preservation in clinical stages IA and IC in premenopausal women with clear cell carcinoma. A total of 741 premenopausal women were identified that fulfilled the inclusion criteria. According to the available information, the uterine preservation rate was $14.5 \%$ (96/663), while the ovarian preservation rate was $28.1 \%(71 / 253)$. The 5 -year overall survival rate was $90.8 \%$ for women who did not undergo hysterectomy in comparison with $87.7 \%$ for those who underwent hysterectomy $(\mathrm{P}=0.290)$. Likewise, the 5 -year overall survival rates in the ovarian preservation and bilateral oophorectomy groups were $92.6 \%$ and $85 \%$, respectively $(\mathrm{P}=0.060)$. After adjusting the analysis for the clinical stage of the disease (IA $v s$. IC), uterine and ovarian preservation were not associated with reduced general or specific cancer-associated mortality (24). Yoshihara et al., in 2019, evaluated prognostic factors in 103 women with stage I clear cell carcinoma and performed fertilitysparing procedures in 21 of the patients; the authors found that clinical stages IC2 and IC 3 were the only independent prognostic factors associated with tumor recurrence, with no differences in recurrence or survival between women treated with radical surgery or fertilitysparing procedures (25).

\section{Borderline tumors}

Borderline tumors represent $14.15 \%$ of all primary ovarian tumors. The two most common histological types are serous and mucinous. Approximately one-third of borderline neoplasms occur in women under 40 years of age who have not completed their desire for fertility. This group of patients is more likely to have a good prognosis (clinical stage I patients have a 5 -year survival rate of 99\%). The risk of recurrence after fertility-sparing surgery is $7-30 \%$ (26,27).

A systematic review of more than 120 retrospective studies reported the efficacy of conservative treatment in borderline tumors (28).

Women with borderline tumors in clinical stage I can be treated with cystectomy or unilateral oophorectomy with 
recurrence rates of $13 \%$ in a 3-6-year follow-up, a risk of $1.6 \%$ for invasive disease, a mortality of $0.5 \%$ and diseasefree survival at 70 months of approximately $89 \%$ (26). Delle Marchette et al., in 2018, reported a recurrence rate of $33.5 \%$ after a follow-up of 13.5 years and attributed this high rate of recurrence to the long follow-up, and the most important results were those related to the pregnancy rate of $82.5 \%$ (29). The diagnosis of borderline tumors can be incidental during surgical intervention for benign ovarian tumors, and experience and training in gynecologiconcology is required for staging during the surgical treatment. Reproductive results are higher in borderline tumors than in early-stage EOC; Chevrot et al. and Plett et al. reported pregnancy rates of $62 \%$ in patients with borderline tumors and $85 \%$ in patients with early-stage EOC, respectively $(30,31)$.

\section{Fertility preservation methods}

The cryopreservation of oocytes can be an option in women under 40 years old with a $B R C A$ mutation or other high-risk hereditary genes related to ovarian cancer such as $R A D 51 C$. The cryopreservation of ovarian tissue is not recommended in patients with EOC treated conservatively due to the increased risk of malignant transformation $(27,32)$.

\section{Oncological outcomes}

In a systematic review that included 1,150 women with EOC who were treated with conservative surgery, 139 (12\%) had recurrence, with 124 cases of stage I disease, 14 cases of stage II disease, and 1 case of stage III disease (33). According to a study of the National Cancer Database of the United States of America (NCDB) by Melamed et al., there was no difference related to the risk of death between standard surgery and fertility-sparing treatment (34). In 2020, Crafton et al. conducted a retrospective cohort study from two data sources (SEER/NCDB) of 9,017 women and reported similar findings as Melamed. They concluded that fertility-sparing surgery appeared to be safe for certain women with EOC but was related to poor survival among women with advanced-stage EOC (35).

In a study from Denmark and another study from the Netherlands that were published in 2019, 393 (31.8\%) patients from a series of 1,234 women with EOC clinical stage I were over-staged and had more extensive surgical treatment. Of the above patients, the microscopic malignant spread to both ovaries was just $0.8 \%$, to the ovary surface was $5.8 \%$ and in the peritoneal washing was $10 \%(36)$.

\section{Contralateral ovary recurrence}

The scientific evidence is limited about recurrence in the contralateral ovary, given that only the survival rate can be compared between fertility preservation treatment and radical treatment in a case series. In general, for a stage IA EOC, the recurrence risk on the remaining ovary is $6 \%$ to $13 \%$ (37). Some studies have demonstrated that in a contralateral ovary without evidence of a macroscopic tumor, the risk of microscopic disease is 0 to $2.5 \%(38,39)$.

A review of seven articles focusing on patterns of recurrence showed that the disease-free survival rate after chemotherapy treatment was $82.1 \%(23 / 28)$ for patients with recurrence on the contralateral ovary $v s .19 .2 \%(10 / 52)$ for patients with other recurrence patterns (18). Other studies have also found that patients with only contralateral ovary recurrence have better outcomes than patients with recurrence in other places. The pattern of recurrence is an essential factor that should be taken into account during the selection of patients for conservative treatment. Recurrences after a fertility-sparing treatment in EOC are reported in an extensive range (5-29\%) depending on the published series, with 5 -year overall survival rates of $94 \%(4,13,14,16-18)$.

The prognosis of patients who had a recurrence of disease after fertility-preserving surgery in EOC is the same as for patients with recurrence after receiving a standard treatment, especially in cases of recurrent distant metastatic disease. A study published by du Bois et al. included 913 patients and found that $11.3 \%$ of patients had recurrences in a follow-up of 6 years: recurrence in EOC clinical stage $\mathrm{IB} / \mathrm{IC}$ was almost double than recurrence in clinical stage IA (OR: $1.72,95 \%$ CI: $1.12-2.64, \mathrm{P}<0.05$ ), and the risk of recurrence was four times higher in grade $2-3$ than in grade 1 (OR: 4.26, 95\% CI: 2.31-7.86, $\mathrm{P}<0.0001$ ). Statistical differences were not observed between recurrences in clinical stage IC grade 1 and IA grade 1 (40).

\section{Reproductive outcomes}

Currently, there is evidence about the oncologic outcomes of fertility-sparing treatments and radical treatments in the early stages of EOC showing overall survival rates greater than $90 \%$ and disease-free survival rates from 70 to $88 \%$. In terms of reproductive outcomes, information in the literature is scarce, with fertility rates reported to be $56 \%$ in early-stage EOC and $82.5 \%$ in borderline 
Table 2 Oncologic and reproductive outcomes of fertility-sparing surgery in EOC

\begin{tabular}{|c|c|c|c|c|c|c|c|}
\hline Authors, year & Patients & $\begin{array}{l}\text { Median age } \\
\text { (years) }\end{array}$ & Stage & $\begin{array}{l}\text { Median follow-up } \\
\text { (month) }\end{array}$ & $\begin{array}{l}\text { No. } \\
\text { recurrence }\end{array}$ & $\begin{array}{l}\text { No. pregnancy } \\
\text { outcomes }\end{array}$ & $\begin{array}{l}5 \text { years } \\
\text { DFS }\end{array}$ \\
\hline Satoh et al. 2010, (17) & 211 & 29 & IA [126], IB NR, IC [85] & 78 & $18(8.5 \%)$ & $45 / 84(53 \%)$ & $92.1 \%$ \\
\hline $\begin{array}{l}\text { Kajiyama et al. 2010, } \\
\text { (42) }\end{array}$ & 60 & 30 & $\begin{array}{c}\mathrm{IA}[30], \mathrm{IB}[2], \mathrm{IC}[29], \mathrm{II} \\
{[1], \mathrm{III}[11]}\end{array}$ & 54.7 & $8(13.3 \%)$ & $9(15 \%)$ & $86.7 \%$ \\
\hline Hu et al. 2011, (43) & 94 & 28.3 & IA [46], IB [8], IC [28] & 58.7 & $9(9.6 \%)$ & $12(12.7 \%)$ & $83 \%$ \\
\hline Fruscio et al. 2013, (22) & 240 & 32 & IA [130], IB [2], IC [105] & $\begin{array}{c}9 \text { years } \\
{[12-319 \text { months] }}\end{array}$ & 27 (11.2\%) & $\begin{array}{c}84(80 \%), \\
16 \text { abortions; } \\
68 \text { births }\end{array}$ & $92 \%$ \\
\hline Uzan et al. 2014, (45) & 119 & 29 & IA [79], IB [18], IC [22] & 45 [12-120] & $38(32 \%)$ & $33(27 \%)$ & $61-77 \%$ \\
\hline Lee et al. 2015, (46) & 35 & 28.6 & $\mathrm{IA}$ [21], IC [13], IIC [1] & $104[8-231.6]$ & $6(17.1 \%)$ & NR & $91.3 \%$ \\
\hline Ditto et al. 2015, (13) & 70 & 30 & $\begin{array}{l}\text { IA [46], IB [2], IC [15], } \\
\text { IIA [1], IIC [1], IIIC [5] }\end{array}$ & 76 [39-149] & NR & NR & $85 \%$ \\
\hline Fruscio et al. 2016, (41) & 242 & 31.3 & IA [129], IB [2], IC [103] & 11.9 years & $12 \%$ & NR & $82 \%$ \\
\hline Ghezzi et al. 2016, (14) & 65 & 33 & $\begin{array}{c}\text { IA [42], IB [1], IC [18], } \\
\text { IIB [1], IIIC [3] }\end{array}$ & $38[2-144]$ & 10 (15.4\%) & $22(60 \%)$ & $84.6 \%$ \\
\hline $\begin{array}{l}\text { Ratanasrithong et al. } \\
2017,(47)\end{array}$ & 28 & 28 & IA [48], IB [5], IC [5] & 78 & 4 & $15(51.7 \%)$ & $91 \%$ \\
\hline Chevrot et al. 2020, (30) & 125 borderline & 30 & IA [47], IB-IC [78] & 57 [2-281] & $20(16 \%)$ & $33 / 52(63 \%)$ & $87.6 \%$ \\
\hline Plett et al. 2020, (31) & 95 borderline & 30 & I [77], II [6], III [12] & 64 & $13(13.7 \%)$ & $82.9 \%$ & NR \\
\hline
\end{tabular}

$\mathrm{NR}$, data not reported; DFS, disease-free survival.

tumors $(18,20,33,40,41)$. A summarize of oncologic and reproductive outcomes are described in Table 2.

\section{Other fertility conservation methods}

There are several fertility preservation options. In the case of a patient who requires oncological treatment (radical surgery or chemotherapy), the following can be considered:

* Embryonic cryopreservation is an alternative procedure in cases where there is no therapeutic urgency, given the time required for the procedure. It is not recommended to stimulate the ovaries or to perform this procedure after chemotherapy due to inadequate ovarian function responses (50).

* Oocyte cryopreservation is a suitable option for patients with EOC clinical stage IA treated with unilateral oophorectomy. Oocyte cryopreservation followed by heterotopic implantation or orthotopic implantation is a technique that can be offered to patients who have not reached puberty or who are 
adolescents. The preservation of ovarian tissue is not an option in women with EOC or patients with a high risk of developing $B R C A 1$ and $B R C A 2-$ related cancer (50).

It is still not known whether ovarian stimulation increases the risk of EOC relapse; therefore, it is recommended to restrict the number of cycles (32). The first line of chemotherapy includes taxanes and platinum-based treatment. The American Society of Clinical Oncology Practice Guideline Committee determined that women treated with a higher dosage $\left(>5 \mathrm{~g} / \mathrm{m}^{2}\right)$ of chemotherapeutics have a higher risk (more than $70 \%$ ) of developing ovarian reserve damage. The alkylating agents produce damage to the oocytes through single-chain DNA ruptures and are directed towards cells in every cell cycle stage, mainly affecting primordial follicles (51).

Currently, GnRH antagonists and agonists are used to avoid premature ovarian failure during chemotherapy. The most significant evidence published is in patients with breast cancer who had higher pregnancy rates after treatment. Oocyte cryopreservation could be an option for women under 40 years of age who are carriers of a pathologic mutation in hereditary high-risk genes, such as $B R C A 1$, and will undergo risk reduction oophorectomy $(27,52,53)$.

\section{Follow-up}

After fertility-sparing surgical treatment in EOC, intensive follow-up by a gynecologist-oncologist is essential. The follow-up involves a physical examination and serum tumor marker, such as Ca-125 and HE-4, evaluation every four months for two years and then every 6 months until 5 years. Given the age at presentation, every young patient with EOC should be assessed for hereditary high-risk genes related to ovarian cancer, including BRCA1 and BRCA2. It is recommended that complete surgery (hysterectomy and bilateral salpingo-oophorectomy) in $B R C A$ carriers be performed when the patient no longer has reproductive desire or in women older than 40 years. Some publications disagree with this suggestion, given the low incidence of recurrence $(10,20,54)$.

\section{Recommendations}

(I) Health care providers should discuss fertility-sparing treatment for every woman under 40 years with adnexal tumors and a high suspicion of malignancy $(4,12,18,19,33)$.
(II) Complete staging and strict follow-up by oncological experts (surgeons and pathologists) are mandatory because the stage and histologic characteristics of the tumor are crucial to patient selection for fertilitysparing treatment $(10,19,33)$.

(III) Conservative treatment can be performed for stage IA and IC grade 1 and 2 diseases and stage IC1 according to the new FIGO staging system $(10,19,33,35)$.

(IV) Fertility-sparing therapy could likely be considered for stage I clear-cell tumors but should remain contraindicated for stage IC2/C3 (because of high risk of recurrence) (25).

(V) Ovarian cryopreservation is a safe method, and it could be used in patients with borderline tumors or clinical stage IA disease (32).

(VI) Young women with early-stage EOC must be considered for ovarian-preserving surgery to maintain ovarian function and fertility and to improve quality of life $(11,12,19)$.

(VII) An ovarian function-preservation technique with conservative surgical treatment should be offered based on the current literature. Early-stage EOC in young women is infrequent; on the other hand, it is becoming more frequent for women to delay childbearing, and it is necessary to obtain more information by prospective clinical trials in this population to improve the fertility-sparing treatment options $(4,12,18,27)$.

\section{Acknowledgments}

We would like to thank Christopher Herrick, MD. Funding: None.

\section{Footnote}

Provenance and Peer Review: This article was commissioned by the Guest Editor (Heriberto Medina-Franco) for the series "Ovarian Cancer" published in Chinese Clinical Oncology. The article was sent for external peer review organized by the Guest Editor and the editorial office.

Conflicts of Interest: All authors have completed the ICMJE uniform disclosure form (available at http://dx.doi. org/10.21037/cco-20-38). The series "Ovarian Cancer" was commissioned by the editorial office without any funding or sponsorship. The authors have no other conflicts of interest 
to declare.

Ethical Statement: The authors are accountable for all aspects of the work in ensuring that questions related to the accuracy or integrity of any part of the work are appropriately investigated and resolved.

Open Access Statement: This is an Open Access article distributed in accordance with the Creative Commons Attribution-NonCommercial-NoDerivs 4.0 International License (CC BY-NC-ND 4.0), which permits the noncommercial replication and distribution of the article with the strict proviso that no changes or edits are made and the original work is properly cited (including links to both the formal publication through the relevant DOI and the license). See: https://creativecommons.org/licenses/by-nc-nd/4.0/.

\section{References}

1. Ferlay J, Colombet M, Soerjomataram I, et al. Estimating the global cancer incidence and mortality in 2018: GLOBOCAN sources and methods. Int J Cancer 2019;144:1941-53.

2. Cronin KA, Lake AJ, Scott S, et al. Annual Report to the Nation on the Status of Cancer, part I: National cancer statistics. Cancer 2018;124:2785-800.

3. Hoskins WJ. Epithelial ovarian carcinoma: Principles of primary surgery. Gynecol Oncol 1994;5 5:S91-6.

4. Kajiyama H, Suzuki S, Yoshikawa N, et al. Fertility-sparing surgery and oncologic outcome among patients with earlystage ovarian cancer propensity score- matched analysis. BMC Cancer 2019;19:1235.

5. Herzog TJ. Assessing the adequacy of surgical staging for ovarian cancer. Gynecol Oncol 2006;103:781-2.

6. Halkia E, Spiliotis J, Sugarbaker P. Diagnosis and management of peritoneal metastases from ovarian cancer. Gastroenterol Res Pract 2012;2012:541842.

7. Piver MS, Barlow JJ, Lele SB. Incidence of subclinical metastasis in stage I and II ovarian carcinoma. Obstet Gynecol 1978;52:100-4.

8. Salgado-Ceballos I, Ríos J, Pérez-Montiel D, et al. Is lymphadenectomy necessary in mucinous ovarian cancer? A single institution experience. Int J Surg 2017;41:1-5.

9. Kleppe M, Wang T, Van Gorp T, et al. Lymph node metastasis in stages I and II ovarian cancer: A review. Gynecol Oncol 2011;123:610-4.

10. Armstrong D, Alvarez R, Bakkum-Gamez J, et al. NCCN Clinical Practice Guidelines in Oncology. Ovarian Cancer.
Vol. 1.2020, NCCN. 2020:1-25.

11. Hanatani M, Yoshikawa N, Yoshida K, et al. Impact of age on clinicopathological features and survival of epithelial ovarian neoplasms in reproductive age. Int J Clin Oncol 2020;25:187-94.

12. Morice P, Denschlag D, Rodolakis A, et al. Recommendations of the fertility task force of the european society of gynecologic oncology about the conservative management of ovarian malignant tumors. Int J Gynecol Cancer 2011;21:951-63.

13. Ditto A, Martinelli F, Bogani G, et al. Long-term safety of fertility sparing surgery in early stage ovarian cancer: Comparison to standard radical surgical procedures. Gynecol Oncol 2015;138:78-82.

14. Ghezzi F, Cromi A, Fanfani F, et al. Laparoscopic fertilitysparing surgery for early ovarian epithelial cancer: A multiinstitutional experience. Gynecol Oncol 2016;141:461-5.

15. Depoers C, Martin FA, Nyangoh Timoh K, et al. A Preoperative Scoring System for Adnexal Mass in Children and Adolescents to Preserve Their Future Fertility. J Pediatr Adolesc Gynecol 2019;32:57-63.

16. Zapardiel I, Diestro MD, Aletti G. Conservative treatment of early stage ovarian cancer: Oncological and fertility outcomes. Eur J Surg Oncol 2014;40:387-93.

17. Satoh T, Hatae M, Watanabe Y, et al. Outcomes of fertility-sparing surgery for stage I epithelial ovarian cancer: A proposal for patient selection. J Clin Oncol 2010;28:1727-32.

18. Tomao F, Di Pinto A, Sassu CM, et al. Fertility preservation in ovarian tumours. Ecancermedicalscience 2018;12:885.

19. Oktay K, Harvey BE, Loren AW. Fertility Preservation in Patients With Cancer: ASCO Clinical Practice Guideline Update Summary. J Oncol Pract 2018;14:381-5.

20. Kajiyama H, Mizuno M, Shibata K, et al. Recurrencepredicting prognostic factors for patients with early-stage epithelial ovarian cancer undergoing fertility-sparing surgery: A multi-institutional study. Eur J Obstet Gynecol Reprod Biol 2014;175:97-102.

21. Yokoyama Y, Moriya T, Takano T, et al. Clinical outcome and risk factors for recurrence in borderline ovarian tumours. Br J Cancer 2006;94:1586-91.

22. Fruscio R, Corso S, Ceppi L, et al. Conservative management of early-stage epithelial ovarian cancer: Results of a large retrospective series. Ann Oncol 2013;24:138-44.

23. Kajiyama H, Shibata K, Suzuki S, et al. Is there any possibility of fertility-sparing surgery in patients with 
clear-cell carcinoma of the ovary? Gynecol Oncol 2008;111:523-6.

24. Nasioudis D, Chapman-Davis E, Frey MK, et al. Could fertility-sparing surgery be considered for women with early stage ovarian clear cell carcinoma? J Gynecol Oncol 2017;28:e71.

25. Yoshihara M, Kajiyama H, Tamauchi S, et al. Prognostic factors and effects of fertility-sparing surgery in women of reproductive age with ovarian clear-cell carcinoma: A propensity score analysis. J Gynecol Oncol 2019;30:e102.

26. Zanetta G, Rota S, Chiari S, et al. Behavior of borderline tumors with particular interest to persistence, recurrence, and progression to invasive carcinoma: A prospective study. J Clin Oncol 2001;19:2658-64.

27. Sonigo C, Sermondade N, Benard J, et al. The past, present and future of fertility preservation in cancer patients. Vol. 11, Future Oncology. Future Oncol 2015;11:2667-80.

28. Skírnisdóttir I, Garmo H, Wilander E, et al. Borderline ovarian tumors in Sweden 1960-2005: Trends in incidence and age at diagnosis compared to ovarian cancer. Int J Cancer 2008;123:1897-901.

29. Delle Marchette M, Ceppi L, Andreano A, et al. Oncologic and fertility impact of surgical approach for borderline ovarian tumours treated with fertility sparing surgery. Eur J Cancer 2019;111:61-8.

30. Chevrot A, Pouget N, Bats AS, et al. Fertility and prognosis of borderline ovarian tumor after conservative management: Results of the multicentric OPTIBOT study by the GINECO \& TMRG group. Gynecol Oncol 2020;157:29-35.

31. Plett H, Harter P, Ataseven B, et al. Fertility-sparing surgery and reproductive-outcomes in patients with borderline ovarian tumors. Gynecol Oncol 2020;157:411-7.

32. Schüring AN, Fehm T, Behringer K, et al. Practical recommendations for fertility preservation in women by the FertiPROTEKT network. Part I: Indications for fertility preservation. Arch Gynecol Obstet 2018;297:241-55.

33. Bentivegna E, Gouy S, Maulard A, et al. Fertility-sparing surgery in epithelial ovarian cancer: A systematic review of oncological issues. Ann Oncol 2016;27:1994-2004.

34. Melamed A, Rizzo AE, Nitecki R, et al. All-cause mortality after fertility-sparing surgery for stage I epithelial ovarian cancer. In: Obstetrics and Gynecology. Lippincott Williams and Wilkins; 2017: 71-9.

35. Crafton SM, Cohn DE, Llamocca EN, et al. Fertilitysparing surgery and survival among reproductive-age women with epithelial ovarian cancer in 2 cancer registries. Cancer 2020;126:1217-24.

36. Hengeveld EM, Zusterzeel PLM, Lajer H, et al. The value of surgical staging in patients with apparent early stage epithelial ovarian carcinoma. Gynecol Oncol 2019;154:308-13.

37. Uzan C, Courbiere B, Chabbert-Buffet N. Epithelial ovarian cancer and fertility preservation: Article drafted from the French Guidelines in oncology entitled "Initial management of patients with epithelial ovarian cancer" developed by FRANCOGYN, CNGOF, SFOG, GINECO-ARCAGY under the aegis of CNG. Gynecol Obstet Fertil Senol 2019;47:180-6.

38. Tomao F, Peccatori F, Pup L del, et al. Special issues in fertility preservation for gynecologic malignancies. Crit Rev Oncol Hematol 2016;97:206-19.

39. Benjamin I, Morgan MA, Rubin SC. Occult bilateral involvement in Stage I epithelial ovarian cancer. Gynecol Oncol 1999;72:288-91.

40. du Bois A, Heitz F, Harter P. Fertility-Sparing Surgery in Ovarian Cancer: A Systematic Review. Onkologie 2013;36:436-43.

41. Fruscio R, Ceppi L, Corso S, et al. Long-term results of fertility-sparing treatment compared with standard radical surgery for early-stage epithelial ovarian cancer. Br J Cancer 2016;115:641-8.

42. Kajiyama H, Shibata K, Suzuki S, et al. Fertility-sparing surgery in young women with invasive epithelial ovarian cancer. Eur J Surg Oncol 2010;36:404-8.

43. $\mathrm{Hu}$ J, Zhu LR, Liang ZQ, et al. Clinical outcomes of fertility-sparing treatments in young patients with epithelial ovarian carcinoma. J Zhejiang Univ Sci B 2011;12:787-95.

44. Cheng X, Cheng B, Wan X, et al. Outcomes of conservative surgery in early epithelial ovarian carcinoma. Eur J Gynaecol Oncol 2012;33:93-5.

45. Uzan C, Muller E, Kane A, et al. Prognostic factors for recurrence after conservative treatment in a series of 119 patients with stage I serous borderline tumors of the ovary. Ann Oncol 2014;25:166-71.

46. Lee JY, Jo YR, Kim TH, et al. Safety of fertility-sparing surgery in primary mucinous carcinoma of the ovary. Cancer Res Treat 2015;47:290-7.

47. Ratanasrithong P, Benjapibal M. Pregnancy outcomes after conservative surgery for early-stage ovarian neoplasms. Asian Pac J Cancer Prev 2017;18:2083-7.

48. Jiang X, Yang J, Yu M, et al. Oncofertility in patients with stage I epithelial ovarian cancer: fertility-sparing surgery 


\section{Page 10 of 10}

in young women of reproductive age. World J Surg Oncol 2017;15:154.

49. Yin J, Wang Y, Shan Y, et al. Pregnancy and oncologic outcomes of early stage low grade epithelial ovarian cancer after fertility sparing surgery: a retrospective study in one tertiary hospital of China. J Ovarian Res 2019;12:44.

50. Whyte JS, Hawkins E, Rausch M, et al. In vivo oocyte retrieval in a young woman with ovarian cancer. Obstet Gynecol 2014;124:484-6.

51. Sonigo C, Beau I, Binart N, et al. The Impact of Chemotherapy on the Ovaries: Molecular Aspects and the Prevention of Ovarian Damage. Int J Mol Sci 2019;20:5342.

52. Rodriguez-Wallberg K, Turan V, Munster P, et al. Can

Cite this article as: Pérez-Quintanilla $M$, del Real-Ordoñez S, Gallardo-Alvarado L, Cantu-de Leon D. Fertility-sparing treatment for epithelial ovarian cancer: a literature review. Chin Clin Oncol 2020;9(4):48. doi: 10.21037/cco-20-38 ovarian suppression with gonadotropin-releasing hormone analogs $(\mathrm{GnRHa})$ preserve fertility in cancer patients? Ann Oncol 2016;27:357.

53. Munhoz RR, Pereira AAL, Sasse AD, et al. Gonadotropinreleasing hormone agonists for ovarian function preservation in premenopausal women undergoing chemotherapy for early-stage breast cancer: A systematic review and meta-analysis. JAMA Oncol 2016;2:65-73.

54. Rodolakis A, Biliatis I, Morice P, et al. European Society of Gynecological Oncology Task Force for Fertility Preservation: Clinical Recommendations for FertilitySparing Management in Young Endometrial Cancer Patients. Int J Gynecol Cancer 2015;25:1258-65. 